\title{
Suitability of internal transcribed spacers (ITS) as markers for the population genetic structure of Blastocystis spp
}

Guiehdani Villalobos ${ }^{1}$, Guadalupe Erendira Orozco-Mosqueda², Merle Lopez-Perez², Eduardo Lopez-Escamilla ${ }^{3}$, Alex Córdoba-Aguilar ${ }^{1}$, Lucia Rangel-Gamboa ${ }^{3}$, Angelica Olivo-Diaz ${ }^{3}$, Mirza Romero-Valdovinos³, Pablo Maravilla ${ }^{3^{*}}$ and Fernando Martinez-Hernandez ${ }^{3^{*}}$

\begin{abstract}
Background: The purpose of this study was to assess the genetic variation and differentiation of Blastocystis subtypes (STs) recovered from symptomatic children by analysing partial sequences of the small subunit rDNA gene region (SSUrDNA) and internal transcribed spacers (1 and 2) plus the 5.85 region (ITS, ITS1 + 5.8S + ITS2) and comparing with isolates from other countries.

Findings: Faecal samples from 47 Blastocystis-infected children with gastrointestinal symptoms and negative for pathogenic enterobacteria were analysed. PCR was performed on DNA from all the samples to identify Blastocystis STs, amplifying a fragment of SSUrDNA and the ITS region. The amplicons were purified and sequenced, and consensus sequences were submitted to GenBank; afterwards, SSUrDNA sequences were analysed for genetic diversity according to geographic area. Regarding the Blastocystis STs found, 51\% were ST1, 23\% ST2, 19\% ST3 and 2\% ST7. For ITS, a haplotype network tree and Bayesian inference revealed the presence of two novel variants of ST1, clustering some sequences into ST1A and ST1B. The values of nucleotide diversity $(\pi)$ and haplotype polymorphism ( $\theta$ ) for ST1, ST2 and ST3 ranged from 0 to 1, whereas the ratio of genetic differentiation $\left(F_{S T}\right) /$ migration index (Nm) showed the highest differentiation between Libya and Thailand-Philippines for ST2 (0.282/0.63). In contrast, a high flow gene was observed between Czech Republic-Denmark-Holland-Spain and USA-Mexico-Colombia for ST1 (0.003/84).

Conclusion: Our data on genetic differentiation and gene flow might explain the differences for the prevalence of Blastocystis STs. Moreover, the ITS region could be used as a genetic marker to assess genetic variation in this parasite.
\end{abstract}

Keywords: Blastocystis spp, Internal transcribed spacers, Blastocystis subtypes, Genetic variation

\section{Findings}

Blastocystis spp are very common intestinal parasites of humans and animals, with a prevalence that varies from country to country and among various communities within the same country [1-3]. In addition, this parasite shows extensive polymorphisms, as reflected by microscopy or molecular analysis. Such polymorphisms have allowed for the recognition of at least 17 genetic subtypes

\footnotetext{
*Correspondence: maravillap@yahoo.com; fherxyz@yahoo.com

${ }^{3}$ Hospital General "Dr. Manuel Gea Gonzalez", Calzada de Tlalpan 4800,

Mexico 14080, DF, Mexico

Full list of author information is available at the end of the article
}

(STs) in the genus Blastocystis based on the analysis of its small subunit rDNA (SSUrDNA) [2,4-8]. In eukaryotes, DNA sequences coding for rDNA genes constitute transcription units located on nuclear chromosomes, which are organised to form a simple multigenic family comprising a high number of repeated copies in tandem. The internal transcribed spacer includes two spacers, ITS1 and ITS2, separated by the $5.8 \mathrm{~S}$ rRNA gene. These spacer regions evolve much faster than coding regions because substitutions occurring in spacers may be considered neutral mutations without any constraints. Therefore, the large amount of research available with regard to the usefulness 
of ITS sequences as excellent markers for species distinction has led scientists to consider both, but mainly ITS-2, as the best tool for problematic taxa, such as cryptic species. Furthermore, the $5.8 \mathrm{~S}$ rRNA gene, although being too short to effectively indicate robust phylogenies across large time scales, shows levels of gene conservation similar to SSUrDNA, which is the most frequently used region for genetic typing analyses in Blastocystis $[9,10]$.

As there is scarce knowledge of the evolution, ecology, and population genetics in this parasite, the purpose of the present study was to assess the genetic variation of Blastocystis STs recovered from symptomatic children from Michoacan state, Mexico, by analysing partial SSUrDNA sequences and internal transcribed spacers (1 and 2) plus the $5.8 \mathrm{~S}$ region (ITS, ITS $1+5.8 \mathrm{~S}+\mathrm{ITS} 2$ ) and comparing with isolates from other countries.

Frozen faecal samples from 47 children infected by Blastocystis (22 males, 25 females, mean age of $8 \pm 3.3$ years), who were treated at the Hospital Infantil de Morelia "Eva Samano de Lopez Mateos" due to gastrointestinal symptoms and were negative for pathogenic enterobacteria, were analysed. Clinical and demographic data were obtained from medical records, and information about the Blastocystis load (reported as "more than" or "less than" five Blastocystis cells per 40X field) was obtained from laboratory files; variables were analysed by $x^{2}$ tests. The Ethics and Research Committee of the hospital approved the study, and informed consent was obtained from one parent of each child.

Stool DNA was extracted from approximately $250 \mathrm{mg}$ faeces using QIAamp DNA Stool Mini Kit (QIAGEN Inc., Germany). A partial SSUrDNA sequence ( $\sim 500 \mathrm{bp}$ ) was obtained using the primers reported by Santín et al. [11] A new specific set of primers for amplifying the ITS1 + 5.8S + ITS2 (ITS) region was designed based on the alignment of highly conserved areas that delimited this region of available Blastocystis sequences and other related organisms in GenBank (Blastocystis hominis, AY125914-AY125919; Proteromonas lacertae, AY224080; Fucus vesiculosus, EF625890, AF102930, AF102913, AF1 02920, AF102929; Thalassiosira pseudonana, HF565129HF565132; Laminaria digitata, FJ042772, FJ042773, FJ0 42764). The designed forward and reverse primers were ITS_Blas_F (5' -GGAAGGTGAAGTCGTAACAAG-3') and ITS_Blas_R (5'-CAGCAGGTCTTCTTRCTTGA-3').

DNA $(2 \mu \mathrm{L})$ was used to amplify the genomic sequences in a $25-\mu \mathrm{L}$ PCR reaction. For ITS1-5.8S-ITS2 region amplification, the reaction contained $200 \mathrm{pmol}$ of each nucleotide, $1 \mathrm{X}$ PCR buffer $(8 \mathrm{mM}$ Tris- $\mathrm{HCl}, \mathrm{pH} 8,20 \mathrm{mM} \mathrm{KCl}$, $1 \mathrm{mM} \mathrm{MgCl} 2$ ), $1 \mathrm{X}$ dNTPs, $0.01 \mathrm{mg}$ BSA, and $1 \mathrm{U} \mathrm{Taq}$ DNA Polymerase (Promega). After the first denaturation step at $94^{\circ} \mathrm{C}$ for $5 \mathrm{~min}, 35$ cycles of denaturation at $94^{\circ} \mathrm{C}$ for $30 \mathrm{~s}$, annealing at $60^{\circ} \mathrm{C}$ for $45 \mathrm{~s}$, and extension at $72^{\circ} \mathrm{C}$ for $30 \mathrm{~s}$ were performed, followed by a final extension step at $72^{\circ} \mathrm{C}$ for $10 \mathrm{~min}$. The amplicons were subjected to electrophoresis in $1.2 \%$ agarose gels and then purified and sequenced on both strands by a commercial service.

All sequences were subjected to a BLAST search in the GenBank database; multiple alignments were performed using the CLUSTAL W [12] and Muscle [13] programmes with manual adjustment in MEGA 5.05 software [14]. The best fit model of nucleotide substitution was determined using the Akaike Information Criterion in Modeltest version 3.7 software [15]; for both markers, it was the Hasegawa Kishino Yano model with gamma distribution and invariable sites. The phylogenetic reconstruction using Bayesian inference was performed with the Mr. Bayes 3.1.2 programme [16-18]. The analysis was performed for 10 million generations with sampling trees every 100 generations. Trees with scores lower than those at the stationary phase (burn-in) were discarded, and the trees that reached the stationary phase were collected and used to build majority consensus trees. Other sequences of both markers were obtained from GenBank and used as subtype references. A Median Joining Network analysis [19] was generated using NETWORK 4.611 software (fluxus-engineering.com) with the default settings and assumptions. A genetic diversity analysis within and between populations was performed using DnaSPv4 [20] and included nucleotide diversity $(\pi)$, haplotype polymorphism $(\theta)$, gene flow $(\mathrm{Nm})$ and genetic differentiation index $\left(\mathrm{F}_{\mathrm{ST}}\right)$. These indexes refer to the following: $\pi$, the average proportion of nucleotide differences between all possible pairs of sequences in the sample; $\theta$, the proportion of nucleotide sites that are expected to be polymorphic in any suitable sample from this region of the genome. Both indexes are used to assess polymorphisms at the DNA level and to monitor diversity within or between ecological populations and examine the genetic variation in related species or their evolutionary relationships. $\mathrm{F}_{\mathrm{ST}}$ is a typical genetic statistic used to measure differentiation between or among populations. The common used values for genetic differentiation are as follows: 0 to 0.05 , small; 0.05 to 0.15 , moderate; 0.15 to 0.25 , great; values above 0.25 indicate huge genetic differentiation. The gene flow or migration index $(\mathrm{Nm})$ refers to the movement of organisms among subpopulations; those strongly differentiated have an $\mathrm{Nm}<<1$, whereas an $\mathrm{Nm}>4$ behaves as a single panmictic unit [21].

Table 1 summarises the clinical, parasitological and genetic data of the infected children. Although 47 faecal samples were analysed, clinical information for 7 patients was not recovered because the clinical records were incomplete and the parent who gave informed consent was not sure of the symptoms. Co-infection was common with other commensal single protozoa including Endolimax nana (19\%), Entamoeba coli (15\%) and Entamoeba hartmanni (13\%). Only 10 samples (21\%) presented $>5$ 
Table 1 Demographic, clinical data and Blastocystis subtype in children from Michoacan, Mexico

\begin{tabular}{|c|c|c|c|c|c|c|}
\hline \multirow[t]{2}{*}{ Sample } & \multirow[t]{2}{*}{ Gender/age } & \multirow[t]{2}{*}{ Symptoms } & \multirow[t]{2}{*}{ Co-infections } & \multirow[t]{2}{*}{ Parasite load* } & \multicolumn{2}{|c|}{ Subtype (GenBank access) } \\
\hline & & & & & SSUrDNA $^{\ddagger}$ & $\mathrm{ITS}^{\S}$ \\
\hline 1 & $\mathrm{M} / 8$ & $6,7,10$ & - & $<5$ & $1(\mathrm{KM} 213425)$ & 1B (KM213469 \\
\hline 2 & $F / 9$ & $1,4,7,10$ & $\begin{array}{l}\text { Endolimax nana Entamoeba } \\
\text { histolytica/E. dispar }\end{array}$ & $<5$ & 1 (KM213426) & ND \\
\hline 3 & $M / 5$ & ND & - & $>5$ & 1 (KM213427) & 1A (KM213470) \\
\hline 4 & $F / 10$ & $2,3,4,5,7,8,9,10$ & E. nana, Entamoeba hartmanni & $>5$ & $1($ KM213428) & 1B (KM213471) \\
\hline 5 & $\mathrm{~F} / 7$ & $1,2,3,4,6,9,10$ & - & $<5$ & $1($ KM213429) & 1B (KM213472) \\
\hline 6 & $\mathrm{~F} / 5$ & ND & Entamoeba coli & $>5$ & 1 (KM213430) & 1B (KM213473) \\
\hline 7 & $M / 9$ & $1,2,3,4,5,6,10,11$ & - & $>5$ & $1($ KM213431) & 1B (KM213474) \\
\hline 8 & $M / 4$ & ND & - & $<5$ & ND & 1A (KM213475) \\
\hline 9 & $M / 13$ & $3,4,6,7,9,11$ & - & $<5$ & 1 (KM213432) & 1B (KM213476) \\
\hline 10 & $\mathrm{M} / 9$ & $1,2,3,4,5,7,8,9,11$ & E. nana, E. coli & $>5$ & 1 (KM213433) & 1A (KM213477) \\
\hline 11 & $M / 4$ & $1,3,6,7$ & E. coli & $<5$ & 1 (KM213434) & 1B (KM213478) \\
\hline 12 & $F / 10$ & $2,3,4,8,9,10$ & - & $>5$ & 1 (KM213435) & 1B (KM213479) \\
\hline 13 & $M / 9$ & $1,2,3,4,7$ & - & $>5$ & 1 (KM213436) & 1A (KM213480) \\
\hline 14 & $F / 5$ & $2,3,6,10$ & E. nana & $<5$ & 1 (KM213437) & 1B (KM213481) \\
\hline 15 & $M / 13$ & $4,10,11$ & E. coli & $<5$ & 1 (KM213438) & 1B (KM213482) \\
\hline 16 & $F / 5$ & $4,10,11$ & E. nana & $<5$ & 1 (KM213439) & 1B (KM213483) \\
\hline 17 & $\mathrm{~F} / 7$ & 2,10 & - & $<5$ & 1 (KM213440) & 3 (KM213484) \\
\hline 18 & $F / 5$ & $4,6,10$ & - & $<5$ & 1 (KM213441) & 1A (KM213485) \\
\hline 19 & $\mathrm{~F} / 7$ & 4,7 & E. nana & $<5$ & 1 (KM213442) & 1A (KM213486) \\
\hline 20 & $\mathrm{M} / 7$ & 4,7 & - & $<5$ & 1 (KM213443) & 1A (KM213487) \\
\hline 21 & $F / 4$ & $2,4,6,10$ & E. nana & $<5$ & 1 (KM213444) & 1B (KM213488) \\
\hline 22 & $F / 5$ & $2,3,5,6,7,8,11$ & - & $<5$ & 1 (KM213445) & ND \\
\hline 23 & $M / 10$ & $4,6,7$ & - & $<5$ & 1 (KM213446) & 1B (KM213489) \\
\hline 24 & $\mathrm{M} / 7$ & 5,6 & E. nana & $<5$ & 1 (KM213447) & 1A (KM213490) \\
\hline 25 & $F / 14$ & $1,2,3,4,7,8,9,10$ & - & $<5$ & 1 (KM213448) & 1B (KM213491) \\
\hline 26 & $F / 5$ & $1,2,3,4,7$ & - & $<5$ & 2 (KM213449) & 2 (KM213492) \\
\hline 27 & $M / 4$ & $3,4,6,7$ & - & $<5$ & $2(\mathrm{KM} 213450)$ & 2 (KM213493) \\
\hline 28 & $F / 9$ & $2,3,8$ & E. histolytica/E. dispar, E. nana & $<5$ & $2(\mathrm{KM} 213451)$ & 2 (KM213494) \\
\hline 29 & $M / 11$ & $1,4,7$ & E. coli & $>5$ & $2(\mathrm{KM} 213452)$ & 2 (KM213495) \\
\hline 30 & $F / 6$ & $1,2,3,6,7,10,11$ & $\begin{array}{l}\text { E. coli, E. histolytica/E. dispar, } \\
\text { E. hartmanni }\end{array}$ & $<5$ & $2($ KM213453) & 2 (KM213496) \\
\hline 31 & $F / 6$ & ND & E. coli, E. hartmanni & $<5$ & ND & 2 (KM213497) \\
\hline 32 & $\mathrm{~F} / 7$ & $1,2,3,4,7$ & - & $<5$ & ND & $2(\mathrm{KM} 213498)$ \\
\hline 33 & $M / 13$ & ND & Microsporidia & $<5$ & $2(\mathrm{KM} 213454)$ & $2(\mathrm{KM} 213499)$ \\
\hline 34 & $M / 1$ & $1,2,4,5,8,10$ & E. hartmanni & $<5$ & $2(\mathrm{KM} 213455)$ & 1B (KM213500) \\
\hline 35 & $\mathrm{~F} / 7$ & $2,3,5,7,9$ & E. coli & $>5$ & $2(\mathrm{KM} 213456)$ & $2(\mathrm{KM} 213501)$ \\
\hline 36 & $M / 13$ & 8,10 & - & $<5$ & $2(\mathrm{KM} 213457)$ & 2 (KM213502) \\
\hline 37 & $F / 10$ & $2,3,7,8,9,10$ & E. hartmanni & $<5$ & $2(\mathrm{KM} 213458)$ & $2($ KM213503) \\
\hline 38 & $M / 3$ & ND & - & $<5$ & 3 (KM213459) & 3 (KM213504) \\
\hline 39 & $F / 14$ & $2,3,4,6,9,10$ & E. hartmanni & $<5$ & 3 (KM213460) & $3(\mathrm{KM} 213505)$ \\
\hline 40 & $F / 11$ & ND & Cyclospora cayetanensis & $<5$ & $3(\mathrm{KM} 213461)$ & 3 (KM213506) \\
\hline 41 & $F / 14$ & $2,3,9,10$ & - & $<5$ & $3(\mathrm{KM} 213462)$ & $3(\mathrm{KM} 213507)$ \\
\hline 42 & $F / 9$ & $2,4,6,7$ & - & $<5$ & $3(\mathrm{KM} 213463)$ & 3 (KM213508) \\
\hline
\end{tabular}


Table 1 Demographic, clinical data and Blastocystis subtype in children from Michoacan, Mexico (Continued)

\begin{tabular}{lllllll}
\hline 43 & $\mathrm{M} / 6$ & $2,3,4,8$ & E. nana & $<5$ & $3(\mathrm{KM} 213464)$ & $3(\mathrm{KM} 213509])$ \\
44 & $\mathrm{~F} / 6$ & $2,5,10$ & Trichomonas hominis & $>5$ & $3(\mathrm{KM} 213465)$ & $3(\mathrm{KM} 213510)$ \\
45 & $\mathrm{M} / 6$ & $2,4,6,7,10$ & - & $<5$ & $3(\mathrm{KM} 213466)$ & $3(\mathrm{KM} 213511)$ \\
46 & $\mathrm{M} / 2$ & $2,6,7$ & - & $<5$ & $3(\mathrm{KM} 213467)$ & $3(\mathrm{KM} 213512$ \\
47 & $\mathrm{M} / 8$ & $2,4,7$ & - & $<5$ & $7(\mathrm{KM} 213468)$ & $7(\mathrm{KM} 213513)$ \\
\hline
\end{tabular}

1, Bruxism; 2, Crams/Abdominal pain; 3, Bloating; 4, Constipation; 5, Vomiting; 6, Diarrhea; 7, Flatus; 8, Nausea; 9, Dizziness; 10, Headache; 11, Anorexia; *Parasite load, Blastocystis cells per $40 \mathrm{X}$ field; ${ }^{\text {}}$ SSUrDNA, small subunit rDNA gene; ${ }^{\mathcal{5}}$ ITS, internal transcribed spacers (ITS- $1+5.8 S+$ ITS-2).

Blastocystis stages per 40X field, with the vacuolar form being the most frequent stage found. Regarding Blastocystis STs, 43 sequences were obtained for SSUrDNA and 46 for ITS. For five samples, we did not have a sufficient amount of DNA with adequate quality to obtain amplicons, most likely due to the activity of several DNases that degrade nucleic acids and therefore decreased the DNA concentration in the samples [22]. A BLAST search confirmed that each sequence matched Blastocystis. All amplicons for SSUrDNA were $\sim 500$ bp. For ITS, the amplicons ranged from 530 to $620 \mathrm{bp}$, showing products of $\sim 550, \sim 530, \sim 620$ and $\sim 590$ bp for ST1, 2, 3 and 7, respectively. Regarding Blastocystis STs, $51 \%$ were ST1, $23 \%$ ST2, $19 \%$ ST3 and 2\% ST7 by SSUrDNA and/or ITS. Only two cases (samples 17 and 34) did not match, which might have been due to a phenomenon of coinfection between STs because the sequencing of several clones is required to detect potential co-infections by different STs when SSUrDNA markers are used. No statistical associations between the symptoms, parasite load and Blastocystis STs were found.

Figure 1 shows selected alignments of the highly polymorphic ITS region used in this study, including representative sequences of each ST found. Clear nucleotide differences can be observed along the alignments within STs, particularly for ST1A and ST1B at nucleotide positions 181-242. Phylogenetic trees were built for the SSUrDNA (Figure not shown) and ITS (Figure 2) regions using all available sequences recorded in GenBank. Our ITS sequences were grouped into the clades ST1, $-2,-3$ and -7 ; interestingly, this inference also revealed the presence of two novel variants of ST1, clustering some sequences into ST1A and ST1B. The haplotype network (Figure 3) also exhibited the presence of two novel variants of ST1, which allowed for clearly distinguishing within each ST and showed the great genetic variability between them. The SSUrDNA (270) and ITS (56) sequences of Blastocystis ST1, -2 and -3 from Libya (Africa), Thailand-Philippines-Japan (Asia), Czech Republic-Denmark-Holland-Spain (Europe), and USAColombia (North and Latin America) deposited in the GenBank databases, as well as our sequences (accession numbers from KM213425 to KM213513), were analysed for their genetic variability. The average nucleotide diversity $(\pi)$ and haplotype polymorphism $(\theta)$ for SSUrDNA was $0.0179 \pm 0.0112$ and $0.0355 \pm 0.0076$, respectively (Figure 4), with $0.0533 \pm 0.0339$ and $0.0642 \pm$ 0.0428 , respectively, found for ITS. The analysis regarding continents showed that $\pi$ and $\theta$ were highest in the European population and lowest in the Libyan population (Figure 4, values inside of the continent image). Information on the $\pi$ and $\theta$ data for human intestinal parasites is rather limited: for helminths, these values range from 0.004 to 0.025 for $\pi$ and from 0.005 to 0.02 for $\theta$ [23-25]; for Giardia lamblia, $\pi$ ranges from 0 to 0.07 [26]; and for Entamoeba histolytica, these values are $\pi=0.004$ and $\theta=0.51$ (Martinez-Hernandez $F$, unpublished data).

The ratio coancestry coefficient $\left(\mathrm{F}_{\mathrm{ST}}\right)$ /migration index $(\mathrm{Nm})$ for SSUrDNA showed the highest differentiation between the Libyan and Thailand-Philippines populations for ST2 (0.282/0.63); in contrast, a high flow gene was observed between the European and American populations for ST1 $(0.003 / 84)$ (Figure 4, values over the arrows). As Africa had few sequences (ranged from 4 to 7 ), the differences in the genetic variation indexes were too large (ranging from 0 to 1 ).

In the present study, ITS was found to be more polymorphic than SSUrDNA (the ITS sequences showed 3 times more variants than SSUrDNA) and thus is a good marker for research on genetic diversity, as for other parasites $[9,10,24,27,28]$. Therefore, its use in population genetic analyses offers reliable results on the genetic variability within populations of this parasite. Regardless, as there are only a few sequences of Blastocystis ITS regions available in GenBank, a robust population genetic analysis using this marker is not possible. In addition, because ITS allows for distinguishing between ST1, $-2,-3$ and -7 using only one PCR directly applied to faecal samples, this marker could be used for Blastocystis ST diagnosis, avoiding the use of PCR-sequencing [11]. However, a limiting factor for this genetic marker is the lack of information about the length of the ITS region of other relevant human STs, such as ST4. An interesting finding in the present study was that the ITS analysis allowed for the clear identification of two novel variants of ST1, as recognised by Bayesian and haplotype network inferences. Recently, Ramírez et al. [29] analysed several faecal 


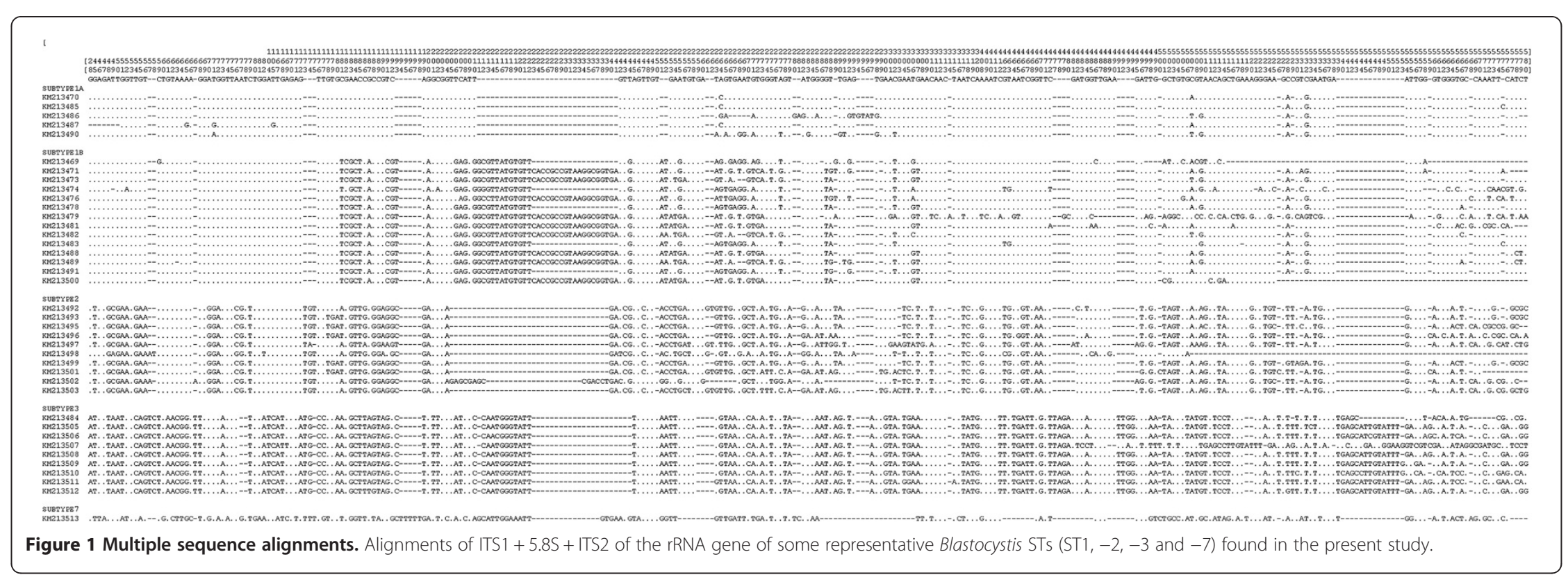




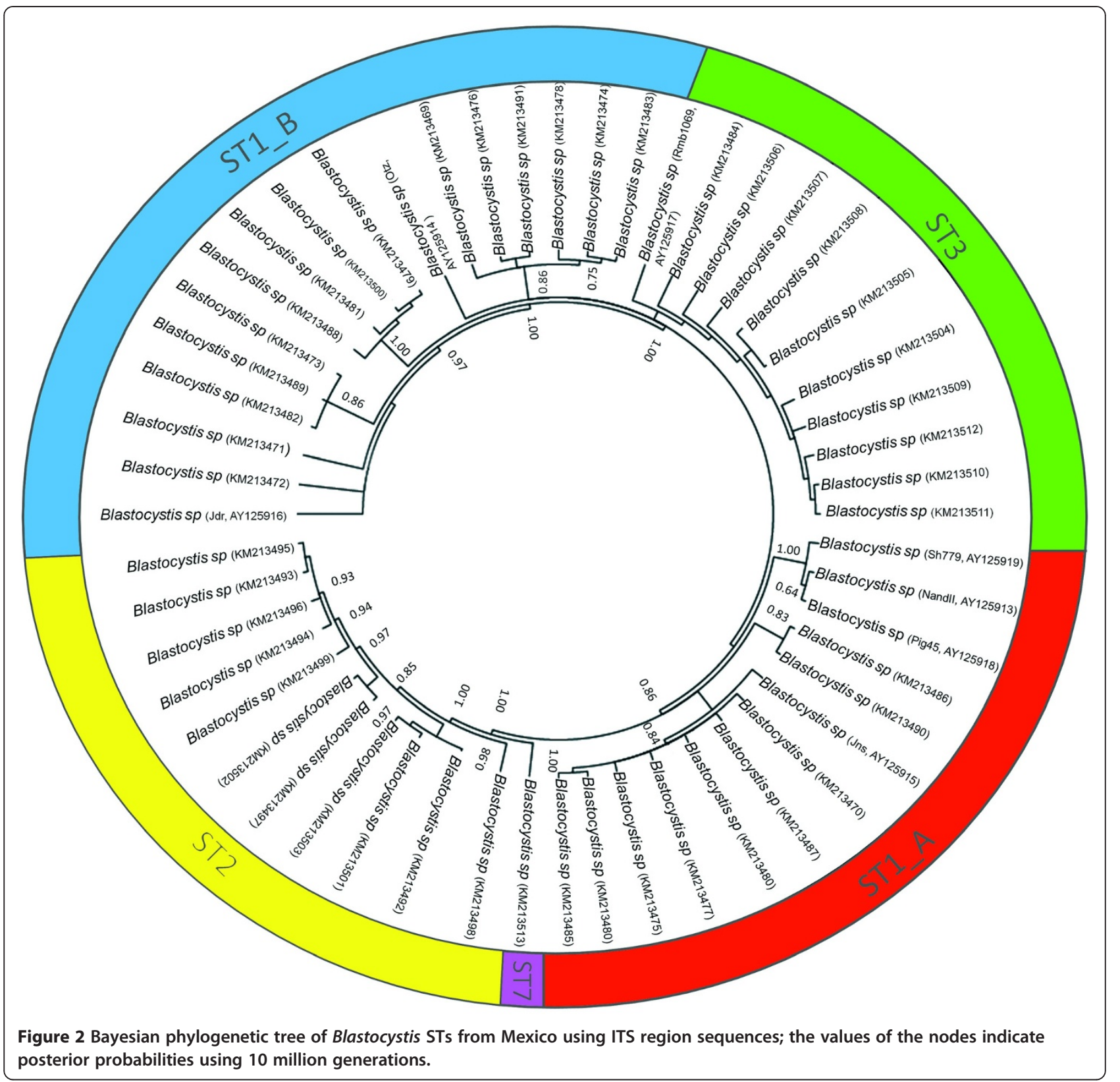

samples containing Blastocystis recovered from humans, birds and other mammals; the ST identification was performed according to DNA barcoding, and a phylogenetic reconstruction using a Maximum Composite Likelihood was performed. Interestingly, the ST1 cluster exhibited two clades, indicating variants, but this was not sufficiently discussed.

The SSUrDNA analysis revealed that ST1 and ST2 showed the lowest genetic differentiation, with a high gene flow between the American and European populations, whereas the match between ST1 and ST2 for the Libyan and American populations showed a higher genetic differentiation with little gene flow. Interestingly, ST3 exhibited the most gene flow (migrants) for ThailandPhilippines vs Libya, America and Europe. Libya had a low number of sequences (ranging from 4 to 7); thus, differences in the variation of the genetic values were also large (ranging from 0 to 1). Alfellani et al. [2] determined the prevalence of Blastocystis STs in populations from Africa and UK and compiled and contrasted the relative distribution of Blastocystis STs across continents, finding a significant variation in ST prevalence between populations. Our results support the analysis of Alfellani et al. [2] because for ST3, these authors found frequencies up to $40 \%$ for major geographic regions, except for America, where the frequency was approximately $25 \%$. 


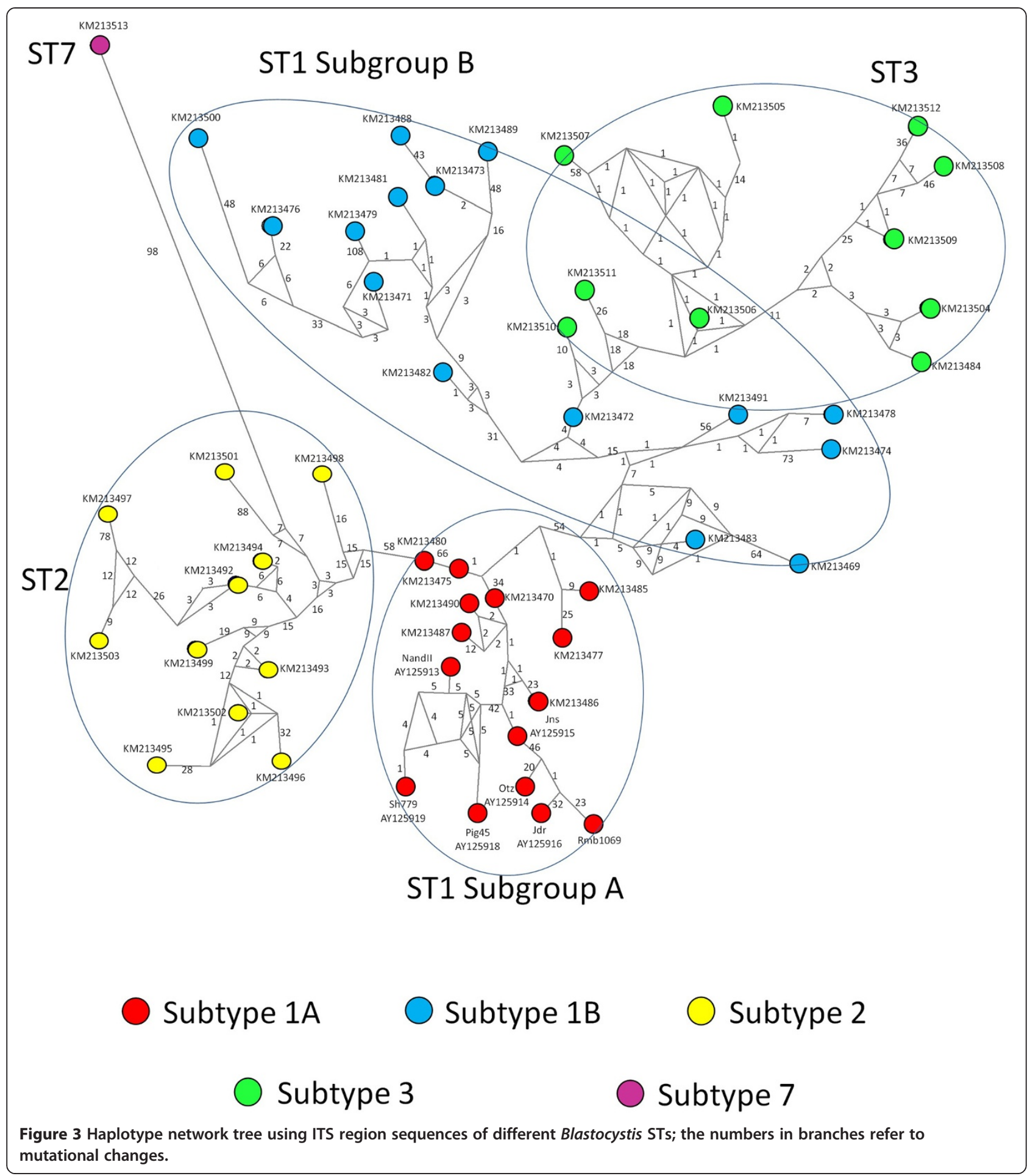

According to our $\mathrm{F}_{\mathrm{ST}} / \mathrm{Nm}$ data, the gene flow $(\mathrm{Nm})$ of $\approx 4$ for America-Europe and America-Africa as well as for America-Asia $(\mathrm{Nm} \approx 9)$ suggest a high migrant flow, but less than Europe-Asia $(\mathrm{Nm} \approx 12)$ and Africa-Asia $(\mathrm{Nm} \approx \infty)$, indicating a vast migrant flow among these areas. For ST2, America shows the highest frequency (up to 30\%), with low values of $\mathrm{Nm}<4$ for America-Africa and America-Asia but $\mathrm{Nm}=33$ for America-Europe; these results could mean that ST2 from America is more isolated than in other major geographic regions. Finally, ST1 shows contrasting values because it was more frequent in America and East/Southeast Asia and lower in Europe and Africa. 


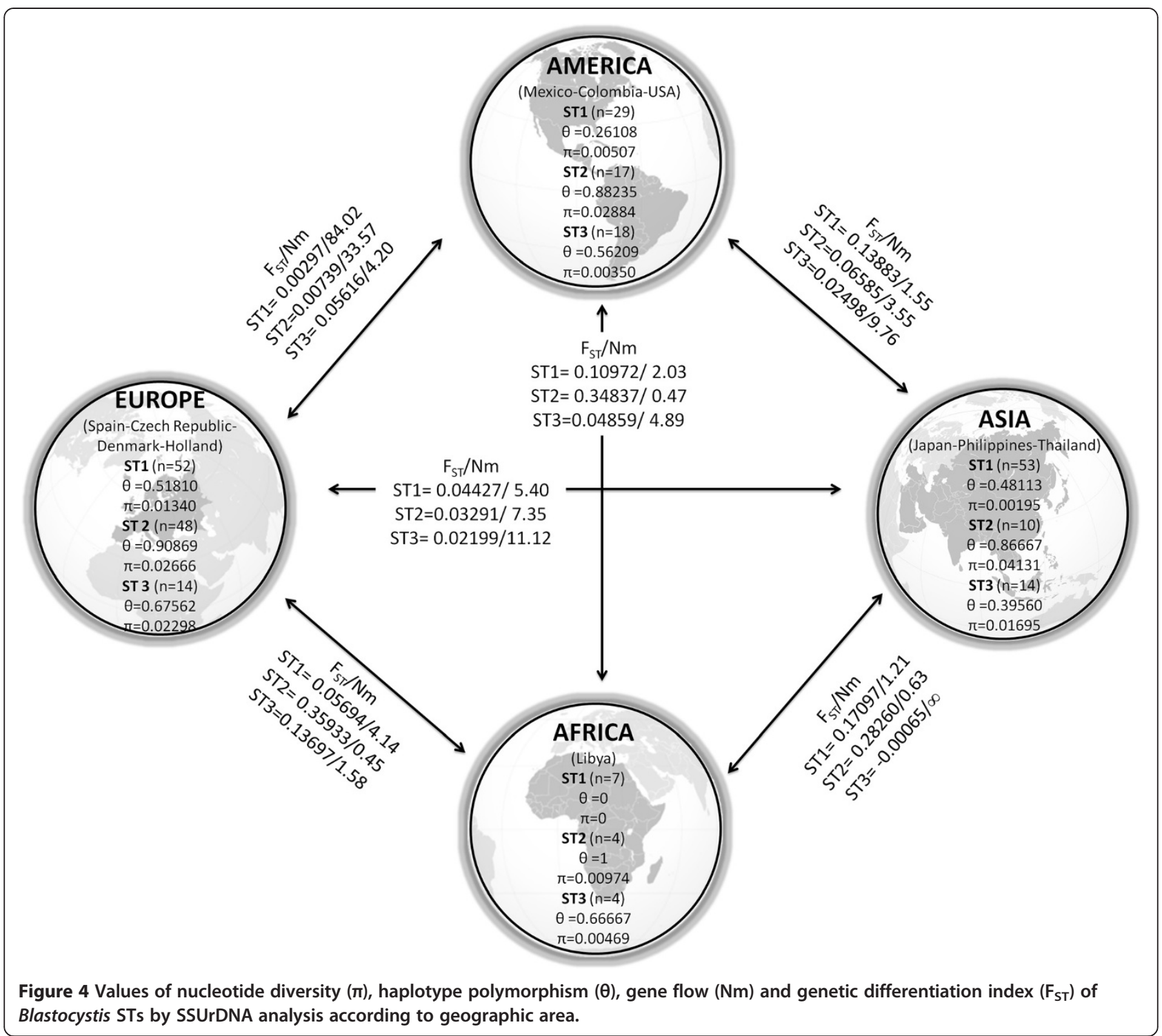

The $\mathrm{F}_{\mathrm{ST}} / \mathrm{Nm}$ data showed $\mathrm{Nm} \leq 4$ among Africa vs Europe-America-Asia, whereas Nm ranged from 4 to 84 between Europe and America-Asia-Africa. Therefore, due to the current globalisation, the variable frequencies observed in ST prevalence might indirectly show the genetic differentiation and gene flow of each ST population around the world.

Poirier et al. [30] described high polymorphism between copies of the SSUrDNA gene of Blastocystis ST7 and Stensvold et al. $[7,31]$ emphasised a remarkable intra-ST genetic diversity and some cryptic host specificity for Blastocystis. Considering that we used part of SSUrDNA in our genetic analyses, we can speculate that these biological features may be a secondary effect due to variation in other genes; most likely by a direct genetic hitchhiking phenomenon [32] or by an indirect association, similar to what has been proposed for other parasites [33].

\section{Abbreviations}

ITS: Internal transcribed spacers; STs: Subtypes; SSUrDNA: Small subunit rDNA gene; $\pi$ : Nucleotide diversity; $\theta$ : Haplotype polymorphism; $F_{S T}$ : Genetic differentiation index; Nm: Migration index.

\section{Competing interests}

The authors declare that they have no competing interests.

\section{Authors' contributions}

GV, GEO-M, ML-P and EL-E collected the samples and performed the coprological assays. GV, MLP and ELE performed the PCR, purification of amplicons and sequencing assays. GV and FMH performed the genetic analysis. AC-A, LR-G, AO-D, MR-V, PM and FM-H formulated the idea, obtained the authorisations and improved the analysis of data. All authors participated during the discussion and writing of the manuscript and approved its final version.

\section{Acknowledgments}

The authors thank Ana Flisser for her critical comments. This work was sponsored by Grants Conacyt 182089 and 168619. 


\section{Author details}

${ }^{1}$ Departamento de Ecología Evolutiva, Instituto de Ecología, Universidad Nacional Autónoma de México, Apdo. Postal 70-275, Ciudad Universitaria, 04510 Mexico, DF, Mexico. ${ }^{2}$ Hospital Infantil de Morelia "Eva Samano de Lopez Mateos", Bosque Cuauhtemoc s/n, Morelia 58000, Michoacan, Mexico. ${ }^{3}$ Hospital General "Dr. Manuel Gea Gonzalez", Calzada de Tlalpan 4800, Mexico 14080, DF, Mexico.

Received: 4 June 2014 Accepted: 26 September 2014

Published online: 03 October 2014

\section{References}

1. Boorom KF, Smith H, Nimri L, Viscogliosi E, Spanakos G, Parkar U, Li LH, Zhou XN, Ok UZ, Leelayoova S, Jones MS: Oh my aching gut: irritable bowel syndrome, Blastocystis, and asymptomatic infection. Parasit Vectors 2008, 1:40.

2. Alfellani MA, Stensvold CR, Vidal-Lapiedra A, Onuoha ES, Fagbenro-Beyioku AF, Clark CG: Variable geographic distribution of Blastocystis subtypes and its potential implications. Acta Trop 2013, 126:11-18.

3. Scanlan PD, Stensvold CR: Blastocystis: getting to grips with our guileful guest. Trends Parasitol 2013, 29:523-529.

4. Dunn LA, Boreham PF, Stenzel DJ: Ultrastructural variation of Blastocystis hominis stocks in culture. Int J Parasitol 1989, 19:43-56.

5. Tan KS: New insights on classification, identification, and clinica relevance of Blastocystis spp. Clin Microbiol Rev 2008, 21:639-665.

6. Ragavan ND, Govind SK, Chye T, Mahadeva S: Phenotypic variation in Blastocystis sp. ST3. Parasit Vectors 2014, 7:404

7. Stensvold CR, Alfellani M, Clark CG: Levels of genetic diversity vary dramatically between Blastocystis subtypes. Infect Genet Evol 2012, 12:263-273.

8. Alfellani MA, Taner-Mulla D, Jacob AS, Imeede CA, Yoshikawa H, Stensvold CR, Clark CG: Genetic diversity of Blastocystis in livestock and zoo animals. Protist 2013, 164:497-509.

9. Mas-Coma S, Bargues MD: Populations, hybrids and the systematic concepts of species and subspecies in Chagas disease triatomine vectors inferred from nuclear ribosomal and mitochondrial DNA. Acta Trop 2009, 110:112-136.

10. Nolan MJ, Cribb TH: The use and implications of ribosomal DNA sequencing for the discrimination of digenean species. Adv Parasitol 2005, 60:101-163.

11. Santín M, Gómez-Muñoz MT, Solano-Aguilar G, Fayer R: Development of a new PCR protocol to detect and subtype Blastocystis spp. from humans and animals. Parasitol Res 2011, 109:205-212.

12. Thompson JD, Higgins DG, Gibson TJ, CLUSTAL W: Improving the sensitivity and progressive multiple sequence alignment through sequence weighting, positions-specific gap penalties and weight matrix choice. Nucleic Acids Res 1994, 22:4673-4680.

13. Edgar RC: MUSCLE: multiple sequence alignment with high accuracy and high throughput. Nucleic Acids Res 2004, 32:1792-1797.

14. Tamura K, Peterson D, Peterson N, Stecher G, Nei M, Kumar S: MEGA5: molecular evolutionary genetics analysis using maximum likelihood, evolutionary distance, and maximum parsimony methods. Mol Biol Evol 2011, 28:2731-2739.

15. Posada D, Crandall KA: Modeltest: testing the model of DNA substitution. Bioinformatics 1998, 14:817-818.

16. Huelsenbeck JP, Ronquist F, Nielsen R, Bollback JP: Bayesian inference of phylogeny and its impact on evolutionary biology. Science 2001, 14:2310-2314.

17. Holder M, Lewis PO: Phylogeny estimation: traditional and Bayesian approaches. Nat Rev Genet 2003, 4:275-284.

18. Ronquis F, Huelsenbeck JP: MrBayes 3: Bayesian phylogenetic inference under mixed models. Bioinformatics 2003, 19:1572-1574.

19. Bandelt HJ, Forster $P$, Röhl A: Median-joining networks for inferring intraspecific phylogenies. Mol Biol Evol 1999, 16:37-48.

20. Rozas J, Sanchez-DelBarrio JC, Messeguer X, Rozas R: DnaSP, DNA polymorphism analyses by the coalescent and other methods. Bioinformatics 2003, 19:2496-2497.

21. Hartl DL, Clark AG: Principles of Population Genetics. Sunderland, Massachusetts: Sinauer Associates, Inc Publishers; 1997.

22. Mathis A, Deplazes P: Copro-DNA tests for diagnosis of animal taeniid cestodes. Parasitol Int 2006, 55:S87-S90.
23. Miranda RR, Tennessen JA, Blouin MS, Rabelo EM: Mitochondrial DNA variation of the dog hookworm Ancylostoma caninum in Brazilian populations. Vet Parasitol 2008, 151:61-67.

24. Martinez-Hernandez F, Jimenez-Gonzalez DE, Chenillo P, Alonso-Fernandez C, Maravilla P, Flisser A: Geographical widespread of two lineages of Taenia solium due to human migrations: can population genetic analysis strengthen this hypothesis? Infect Genet Evol 2009, 9:1108-1114.

25. Sharma M, Fomda BA, Mazta S, Sehgal R, Bagicha Singh B, Malla N: Genetic diversity and population genetic structure analysis of Echinococcus granulosus sensu stricto complex based on mitochondrial DNA signature. PLoS One 2013, 8:12

26. Teodorovic S, Braverman JM, Elmendorf HG: Unusually low levels of genetic variation among Giardia lamblia isolates. Eukaryot Cell 2007, 6:1421-1430.

27. Pomajbíková K, Oborník M, Horák A, Petrželková KJ, Grim JN, Levecke B, Todd A, Mulama M, Kiyang J, Modrý D: Novel insights into the genetic diversity of balantidium and balantidium-like cyst-forming ciliates. PLoS Negl Trop Dis 2013, 7:e2140-e2150.

28. Lopez-Escamilla E, Sanchez-Aguillon F, Alatorre-Fernandez CP, Aguilar-Zapata D, Arroyo-Escalante S, Arellano T, Moncada-Barron D, Romero-Valdovinos M, Martinez-Hernandez F, Rodriguez-Zulueta P, Maravilla P: New Tetratrichomonas species in two patients with pleural empyema. J Clin Microbiol 2013, 51:3143-3146.

29. Ramírez JD, Sánchez LV, Bautista DC, Corredor AF, Flórez AC, Stensvold CR: Blastocystis subtypes detected in humans and animals from Colombia. Infect Genet Evol 2014, 22:223-228.

30. Poirier P, Wawrzyniak I, Albert A, El Alaoui H, Delbac F, Livrelli V: Development and evaluation of a real-time PCR assay for detection and quantification of Blastocystis parasites in human stool samples: prospective study of patients with hematological malignancies. J Clin Microbiol 2011, 49:975-983.

31. Stensvold CR, Suresh GK, Tan KS, Thompson RC, Traub RJ, Viscogliosi E, Yoshikawa H, Clark CG: Terminology for Blastocystis subtypes-a consensus. Trends Parasitol 2007, 23:93-96.

32. Smith JM, Haigh J: The hitch-hiking effect of a favourable gene. Genet Res 1974, 23:23-35.

33. Palafox-Fonseca $H$, Zúñiga $G$, Bobes RJ, Govezensky T, Piñero D, Texco-Martínez L, Fleury A, Proaño J, Cárdenas G, Hernández M, Sciutto E, Fragoso G: Genetic variation in the Cytb gene of human cerebral Taenia solium cysticerci recovered from clinically and radiologically heterogeneous patients with neurocysticercosis. Mem Inst Oswaldo Cruz 2013, 108:914-920.

doi:10.1186/s13071-014-0461-2

Cite this article as: Villalobos et al:: Suitability of internal transcribed spacers (ITS) as markers for the population genetic structure of Blastocystis spp. Parasites \& Vectors 2014 7:461

\section{Submit your next manuscript to BioMed Central and take full advantage of:}

- Convenient online submission

- Thorough peer review

- No space constraints or color figure charges

- Immediate publication on acceptance

- Inclusion in PubMed, CAS, Scopus and Google Scholar

- Research which is freely available for redistribution 